\title{
A Concretização do Trabalho Digno no Mercosul: Dilemas da Integração Regional
}

\author{
Juliane Caravieri Martins Gamba \\ "O último estágio de uma sociedade de operários, que é a sociedade de detentores de \\ empregos, requer de seus membros um funcionamento puramente automático, \\ como se a vida individual realmente houvesse sido afogada no processo vital da \\ espécie, e a única decisão ativa exigida do indivíduo fosse deixar-se levar, \\ por assim dizer, abandonar a sua individualidade, as dores e \\ as penas de viver ainda sentidas individualmente, \\ e aquiescer num tipo funcional de conduta entorpecida e 'tranquilizada'” \\ Hannah Arendt
}

\begin{abstract}
Resumo: Atualmente, predomina a concepção de que o trabalho está intrinsecamente relacionado à dignidade do trabalhador, logo, não é suficiente a concessão de trabalho ao ser humano, é imprescindível que se conceda um trabalho digno, sendo sua concretização um desafio no âmbito dos processos de integração regional, em especial no Mercado Comum do Sul (Mercosul) que envolve Estados possuidores de realidades socioeconômicas e culturais muito diferenciadas. Assim, o presente estudo dividiu-se em quatro partes. Primeiramente, analisou-se o significado do valor do trabalho humano à luz de diferentes saberes, demonstrando a importância de sua compreensão, notadamente em face de seu significado axiológico. A seguir, debruçou-se sobre a análise da concepção de trabalho digno a ser garantido a toda pessoa humana trabalhadora, englobando, ainda, a visão adotada pela Organização Internacional do Trabalho (OIT) em suas declarações internacionais. Por fim, verificou-se a possibilidade de concretização do trabalho digno no Mercosul.
\end{abstract}

Palavras-chave: Trabalho; Dignidade Humana; Integração; Mercosul.

Abstract: Currently, the predominant view that the labor is intrinsically linked to the dignity of the laborer, then, is not sufficient to grant labor to humans, it is imperative to

(*) Professora universitária e advogada; graduada em Ciências Econômicas pela Universidade Estadual Paulista (UNESP), Graduada em Direito e Especialista em Economia Empresarial pela Universidade Estadual de Londrina (UEL), Especialista em Direito do Trabalho pela Universidade Braz Cubas (UBC), Mestre em Direito do Estado (Direito Constitucional) pela Pontifícia Universidade Católica de São Paulo (PUCSP). E-mail: $<$ jcaravierigamba@uol.com.br>. Recebido em 1ํ․5.2010 e aceito em 17.1.2010. 
grant decent labor, and its implementation a challenge in the context of regional integration processes, especially in the Common Market of the South (MERCOSUR), which involves states have socioeconomic and cultural realities of highly differentiated. The present study was divided into four parts. First, we analyzed the significance of the value of human labor in the light of different knowledge, demonstrating the importance of their understanding, especially in view of its significance axiological. Then looked at the design review of decent labor to be guaranteed to every human person working, encompassing also the view adopted by the International Labor Organization (ILO) in its international declarations. Finally, there was the possibility of realizing decent labor in Mercosur.

Keywords: Labor, Human Dignity, Integration, Mercosur. 


\section{INTRODUÇÃo}

Nos primórdios da civilização, o trabalho era a atividade ligada à pesca, à caça, à coleta de frutos e à plantação de alimentos destinados ao sustento do homem, sendo a atividade que garantiria a subsistência e a vida em comunidade.

Após o século XVIII, é notório que os trabalhadores estavam sujeitos a extenuante jornada de trabalho sob precárias condições de higiene e segurança; o ritmo do trabalho era determinado pelas máquinas, de modo que suas habilidades individuais, necessárias no trabalho artesanal, não eram mais exigidas no trabalho fabril, havendo a alienação do trabalhador, que não mais se identificava com a atividade que desenvolvia.

Entretanto, evoluiu-se a concepção do trabalho como intrinsecamente relacionado à dignidade do trabalhador, principalmente após a criação, em 1919, da Organização Internacional do Trabalho (OIT), que concedeu um tratamento uniformizado aos direitos humanos dos trabalhadores, em nível internacional, fundamentado na busca pela concretização do trabalho digno.

Portanto, não era mais suficiente a concessão de trabalho ao ser humano, sendo imprescindível que se concedesse o trabalho digno, isto é, o trabalho que não afrontasse a dignidade do trabalhador, sendo sua concretização um desafio no âmbito dos processos de integração regional, notadamente no caso do Mercado Comum do Sul (Mercosul) que envolve Estados possuidores de realidades socioeconômicas e culturais muito diferenciadas.

Os Estados integrantes do Mercosul são também membros da OIT e ratificaram as principais convenções e declarações que garantiram direitos essenciais aos trabalhadores e buscaram a promoção do pleno emprego, de condições mais equânimes e justas de trabalho, enfim, a concretização fática do trabalho digno.

Somente com a valorização do homem e com o respeito de suas diferenças pelos Estados e pela comunidade, haverá efetivamente a concretização do trabalho digno no Mercosul, rumo a uma integração regional mais equânime e solidária para os povos latino-americanos.

Assim, o presente estudo dividiu-se em quatro partes. Primeiramente, analisou-se o significado do valor do trabalho humano à luz de diferentes saberes, demonstrando a importância de sua compreensão, notadamente em face de seu significado axiológico. A seguir, debruçou-se sobre a análise da concepção de trabalho digno a ser garantido a toda pessoa humana trabalhadora, englobando a visão adotada pela Organização Internacional do Trabalho (OIT) em suas declarações internacionais. Por fim, verificou-se os dilemas para a concretização do trabalho digno no Mercosul.

Como metodologia científica, adotou-se os métodos dedutivo (análise do geral para o particular), dialético (contraposição entre tese e antítese) e histórico-sociológico (investigação de fatos, processos e instituições ao longo do tempo) e, quanto à técnica de pesquisa, utilizou-se a bibliográfico-doutrinária. 
$\mathrm{O}$ artigo analisou a possibilidade de concretização do trabalho digno no Mercosul, buscando produzir conhecimento em tempo de crise das ciências e de busca de novos paradigmas. Portanto, o estudo tentou, na medida do possível, buscar "um caminho real para aceder à verdade” (SANTOS, 1998, p. 74), não objetivando exaurir os questionamentos em relação à temática estudada, mas almejou contribuir para o enriquecimento das discussões.

\section{O VALOR DO TRABALHO HUMANO}

Nos primórdios da civilização, o trabalho era a atividade ligada à pesca, à caça, à coleta de frutos e à plantação de alimentos destinados ao sustento do homem, acompanhou a evolução histórica do próprio ser humano, sendo a atividade que garantiria a subsistência e a vida em comunidade.

À luz da Antropologia Jurídica, Rocha (2008, p. 30) discorre sobre a relação homem-trabalho:

A construção do homem pode ser resumida em Trabalho. O trabalho é para o homem seu "inferno" e seu "paraíso”. Mesmo nas teorias “criacionistas” — a criação divina - o trabalho aparece como fundamento de sua ontologia - a construção de seu ser. Pelo trabalho os hominídeos, ancestrais dos humanos, se transformaram ao longo de milhões de anos e puderam produzir a humanidade tal como a conhecemos em nossos dias - teoria evolucionista. Desde os estudos de Charles Darwin, no século XIX, até hoje, a antropologia e as demais ciências parecem confirmar essa evolução a partir de circunstâncias de necessidade, de sobrevivência material e adaptação à natureza.

No Dicionário Houaiss de Língua Portuguesa (2008), o trabalho possui o significado de "1. esforço incomum; 2. luta, lida, faina; 3. conjunto de atividades produtivas ou criativas que o homem exerce para atingir determinado fim; 4. atividade profissional regular, remunerada ou assalariada"; na Rubrica de Economia Política representa "a atividade humana que, com o auxílio ou não de máquinas, se caracteriza como fator essencial da produção de bens e serviços”.

Abbagno (2007, p. 1147-1148), sob o prisma filosófico, dispõe:

TRABALHO (latim Labor; inglês Labor; francês Travail; alemão Arbeit; italiano Lavoro). Atividade destinada a utilizar as coisas naturais ou a modificar o ambiente para a satisfação das necessidades humanas. O conceito de trabalho implica portanto: 1) a dependência do homem, no que diz respeito à vida e aos seus interesses, em relação à natureza: o que constitui a necessidade; 2 ) a reação ativa a essa dependência, constituída por operações mais ou menos de elevado esforço, sofrimento ou cansaço, que constitui o custo humano do trabalho. Baseia-se sobretudo neste último aspecto a condenação da filosofia antiga e medieval ao trabalho manual (v. Banausia). Também devido a esse aspecto, o trabalho foi considerado pela Bíblia como parte 
da maldição divina decorrente do pecado original (Gênese, III, 19). E no famoso texto de São Paulo o preceito “Quem não quiser trabalhar não coma” deriva da obrigação de não jogar sobre os ombros alheios o cansaço e o sofrimento do trabalho (II Tessal., III, 8-10). No mesmo sentido, Agostinho (De Operibus Monachorum, 178) e Tomás de Aquino ( $S$. Th., II, II, q. 187 a. 3) recomendavam o trabalho como preceito religioso. Na exigência de distribuir entre todos o sofrimento e a degradação do trabalho manual inspiraram-se a Utopia (1516) de Thomas More e a Cidade do Sol (1602) de Campanella, que prescrevem para todos os membros de suas cidades ideais a obrigação do trabalho. Com base nisso, consagrava-se a contraposição entre trabalho manual e atividade intelectual, entre artes mecânicas e artes liberais; também no Renascimento a defesa quase unânime, por parte de literatos e filósofos, da vida ativa diante da vida contemplativa e a condenação unânime do ócio (...). (grifo do autor)

No Dicionário de Sociologia, Johnson (1997, p. 241) aponta:

De modo geral, trabalho é toda atividade que gera um produto ou serviço para uso imediato ou troca. Há muito tempo, sociólogos têm se mostrado interessados em certo número de questões fundamentais sobre o trabalho: como o trabalho é definido e organizado e como isso afeta a experiência do trabalho; como os indivíduos são distribuídos entre as ocupações (em termos de sexo, raça ou composição etária da FORÇA DE TRABALHO; como a organização do trabalho se vincula aos sistemas de ESTRATIFICAÇÃO E DESIGUALDADES; e como ele se relaciona com grandes instituições, como o ESTADO, a RELIGIÃO e a FAMÍLIA). (...)

Em termos jurídicos, Silva (2005, p. 1413) alude:

Trabalho, então, entender-se-á todo esforçofísico, ou mesmo intelectual, na intenção de realizar ou fazer qualquer coisa.

No sentido econômico e jurídico, porém, trabalho não é simplesmente tomado nesta acepção física: é toda ação, ou todo esforço ou todo desenvolvimento ordenado de energias do homem, sejam psíquicas, ou sejam corporais, dirigidas com um fim econômico, isto é, para produzir uma riqueza, ou uma utilidade, suscetível de uma avaliação, ou uma apreciação monetária. Assim, qualquer que seja a sua natureza, e qualquer que seja o esforço que o produz, o trabalho se reputa sempre um bem de ordem econômica, juridicamente protegido.

(...) No sentido constitucional, o trabalho, além de ser assegurado a todos, a fim de que possibilite uma existência digna ao trabalhador, é uma obrigação social. Modernamente, o trabalho é sempre objeto de um contrato, que se estabelece entre trabalhador e empregador, vulgarmente chamado de patrão, no qual se compõem, respeitados os preceitos legais, as condições que se convencionarem, inclusive remuneração, ou salário, e outras vantagens pecuniárias atribuídas ao trabalhador. (...) (grifo do autor) 
A partir do desenvolvimento do modo de produção capitalista, houve a divisão social e técnica do trabalho que transformou este ato, inicialmente tão natural, numa engrenagem do processo de produção. A Revolução Industrial do século XVIII impôs novas formas de produção com o uso de forças motrizes, tais como a máquina a vapor e o tear mecânico que impulsionaram o crescimento da produção fabril. Desse modo, ao ser humano não seria mais suficiente trabalhar para se manter vivo, uma vez que o trabalho passou a representar salário ${ }^{(1)}$ e o trabalhador a ser operário assalariado, ambos integrantes do sistema capitalista, assumindo a forma de mercadorias ou de custos de produção.

Analisando a Revolução Industrial, seus impactos na vida em comunidade, na relação trabalho-capital e na necessidade do direito de pacificar os conflitos sociais no mundo do trabalho, Supiot (2007, p. 164-165) tece os seguintes comentários:

Essa explosão [das novas tecnologias da informação e da comunicação] se insere num processo iniciado com a Revolução Industrial. A exploração das energias fósseis e o progresso dos meios de comunicação haviam causado um primeiro divórcio entre o espaço-tempo das máquinas e o da vida humana. O Direito do Trabalho interveio então para reconstituir um espaço-tempo humanamente suportável. Tendo a iluminação a gás, depois a elétrica, emancipado o trabalho industrial dos ritmos da natureza (dia/noite; verão/inverno) e exposto os operários a um alongamento desmedido da duração do trabalho, o Direito veio limitar a jornada, depois o ano, depois a vida de trabalho. O impossível, o Direito substituiu pela proibição. Foram assim criados de alto a baixo os novos ritmos de vida que ordenam a vida do homem moderno e a organização de seu território: metrô, trabalho, sono, feriados. (...) O maquinismo industrial acarretara profundas subversões na organização do espaço. Sem mão nem cérebro, a máquina tinha necessidade de ser nutrida e guiada pelo homem. A fábrica industrial definiu-se, portanto, ao mesmo tempo pela concentração de um grande número de trabalhadores e pela separação com o habitat e a Cidade. Daí a profusão de problemas que o Direito teve de enfrentar: os da higiene e da segurança, da responsabilidade pelo uso das máquinas, da disciplina e das liberdades coletivas nos locais de trabalho, da organização dos serviços públicos de transporte e de saúde, etc. Nesse contexto histórico, a tipologia dos direitos tende a se indexar a uma tipologia dos locais: transpor a porta da empresa é passar de um universo jurídico para outro.

Em suma, verifica-se que os problemas engendrados pelo processo de industrialização se agravaram pela tendência predatória do laissez-faire ${ }^{(2)}$ capitalista, pois as

(1) Nas sociedades capitalistas, o salário representa o preço oferecido pelo empregador ao empregado pelo dispêndio de sua força de trabalho por determinado período, seja por semana, por mês ou por unidade de produção; é a importância paga pelo empregador ao empregado pela contraprestação dos serviços.

(2) Conforme preceituam Bottomore e Outhwaite (1996, p. 412), "laissez-faire: esta expressão francesa significa 'deixem fazer'. A maioria das explicações atribui o slogan, carregado de conotações políticas, laissez-faire, laissez-passer, que significa 'deixem as pessoas fazerem tal como escolheram, deixem passar as mercadorias', a Vicent de Gournay. Esse slogan tornou-se a palavra de ordem entre os defensores do livre comércio, como Jacques Turgot e outros fisiocratas, e foi rapidamente sistematizado em Inquiry into the Nature and Causes of the Wealth of Nations, de 
precárias condições de trabalho e os baixos salários refletiam uma situação comum a todos os trabalhadores "livres" e assalariados nesse período, inclusive em outros países europeus, tais como: Alemanha, França e Itália que, nos séculos seguintes, implementariam, de modo semelhante, a Revolução Industrial.

Sherman e Hunt (2000, p. 69) sintetizam claramente o processo socioeconômico, político e ideológico que engendrou a Revolução Industrial e "alimentou” o modo de produção capitalista, oprimindo as classes operárias nos séculos XVIII e XIX:

A pressão da demanda, em rápida expansão, e as perspectivas de lucros elevados produziram, no final do século XVIII e no princípio do século XIX, uma "verdadeira explosão da atividade inventiva”. Nesse período de profundas inovações - que se convencionou chamar de Revolução Industrial - a Inglaterra (e, posteriormente, a Europa ocidental e a América do Norte) transformou-se numa sociedade urbana dominada por grandes cidades manufatureiras, nas quais multidões de trabalhadores eram submetidas à disciplina desumanizadora da produção fabril.

Nesse período, a ideologia liberal clássica conquistou, definitivamente, o pensamento econômico e social. A nova ideologia caracterizava os homens como indivíduos essencialmente egoístas, frios, calculistas, indolentes e, de um modo geral, independentes da sociedade a que pertenciam. A análise de Adam Smith sobre o mercado, concebido como a "mão invisível” que canalizava as motivações egoístas dos homens para atividades de maior utilidade social, proporcionou os fundamentos da teoria do laissez-faire. Segundo essa filosofia, competia aos governos assumir exclusivamente as funções que respaldassem e incentivassem as atividades lucrativas.

Finalmente, a teoria populacional de Malthus condenava as medidas sociais destinadas a mitigar o sofrimento dos pobres, não apenas por serem inúteis, mas também por suas consequências socialmente nocivas. A aceitação dessa visão implicava renunciar definitivamente à ética paternalista cristã.

Por sua vez, Marx (2006; 2007), analisando o desenvolvimento histórico das sociedades desde as sociedades pré-capitalistas até a sociedade capitalista propriamente dita, percebeu que o homem estava em contínua interação com a natureza, criando bens que satisfiziam suas necessidades e a este tipo de atividade denominou trabalho. Ele compreendeu o trabalho como algo inerente à própria natureza humana, possuindo um caráter a-histórico, na medida em que estava presente em todas as sociedades, mesmo naquelas não capitalistas, traçando as seguintes considerações:

(...) O trabalho nem sempre foi assalariado, isto é, trabalho livre. O escravo não vendia a sua força de trabalho ao proprietário de escravos, assim como o boi não vende os seus esforços ao camponês. O escravo é vendido, com a sua força de trabalho,

\footnotetext{
Adam Smith, como parte do 'sistema óbvio e simples da liberdade natural' (SMITH, 1776, livro 4, cap. 9). Smith e outros economistas clássicos ampliaram a noção de laissez-faire, de um programa de livre comércio internacional para uma ampla filosofia social. (...) Os deveres do governo seriam então limitados à defesa nacional, à administração da justiça e à provisão de certos bens públicos. (...)”.
} 
de uma vez para sempre, ao seu proprietário. É uma mercadoria que pode passar das mãos de um proprietário para as mãos de um outro. Ele próprio é uma mercadoria, mas a força de trabalho não é uma mercadoria sua. O servo só vende uma parte de sua força de trabalho. Não é ele quem recebe um salário do proprietário de terra: ao contrário, é o proprietário de terra quem recebe dele um tributo. O servo pertence à terra e rende frutos ao dono da terra. $\mathrm{O}$ operário livre, ao contrário, vende-se a si mesmo e, além disso, por partes. Vende em leilão 8, 10, 12, 15 horas da sua vida, dia após dia, a quem melhor pagar, ao proprietário das matérias-primas, dos instrumentos de trabalho e dos meios de subsistência, isto é, ao capitalista (MARX, 2006, p. 37).

Portanto, Marx (2006; 2007) constatou que, na sociedade capitalista após a Revolução Industrial, havia a burguesia possuidora do capital, dos meios de produção e de subsistência e, em contraposição, os trabalhadores "livres" que vendiam a sua força de trabalho para sobreviver, pois não possuíam os meios de produção e de subsistência.

Após o século XVIII, é notório que os trabalhadores estavam sujeitos a extenuante jornada de trabalho sob precárias condições de higiene e segurança; o ritmo do trabalho era determinado pelas máquinas, de modo que suas habilidades individuais, tão necessárias na época do trabalho artesanal, não eram mais exigidas no trabalho fabril, havendo a alienação do trabalhador, que não mais se identificava com a atividade que desenvolvia, concomitantemente com a própria alienação do trabalho que perdeu seu valor intrínseco para a vida do ser humano.

Nesse contexto, em 15 de maio de 1891, a Encíclica Rerum Novarum do Papa Leão XIII - integrante da Doutrina Social da Igreja ${ }^{(3)}$ - conclamou os povos e os Estados a buscarem uma ordem social mais justa, pois “(...) o trabalho tem uma tal fecundidade e tal eficácia que se pode afirmar, sem receio de engano, que ele é a fonte única de onde procede a riqueza das nações” (LESSA, 2004, p. 271). Evidenciou-se o valor do trabalho humano e a necessidade de se aplicar as leis contra as condições indignas e degradantes de trabalho que desonravam a pessoa humana do trabalhador.

A partir desses apontamentos, verifica-se que o trabalho assemelha-se a um caleidoscópio porque está sob constante estudo e análise à luz de diferentes saberes humanos, demonstrando a importância de sua compreensão, notadamente em face de seu significado axiológico.

O trabalho não pode ser dissociado do homem-trabalhador, sendo um valor necessário para a sua existência digna, estando intrinsecamente relacionado à dignidade da pessoa humana ${ }^{(4)}$, pois deve ser obrigação social imposta aos Estados, à comunidade e aos particulares.

(3) Representa o conjunto dos ensinamentos do magistério da Igreja Católica constante em encíclicas e pronunciamentos de papas, tendo por finalidade fixar princípios, critérios e diretrizes gerais a respeito da organização sociopolítica da vida em comunidade.

(4) Para Kant (2008), "tudo possui ou um preço ou uma dignidade. Aquilo que tem preço pode ser substituído por algo equivalente; por outro lado, o que se acha acima de todo preço e, portanto, não admite nada equivalente, encerra uma dignidade”. Garcia (2004, p. 211 ) afirma que “a dignidade da pessoa humana corresponde à compreensão 


\section{A CONCEPÇÃo DE TRABALHO DIGNO}

Ao longo dos séculos, o trabalho foi associado a uma atividade penosa que não traria felicidade e conhecimento ao homem, sendo relegado aos escravos no mundo antigo (sistema escravista), aos servos no medievo (sistema feudal) e ao proletariado na era moderna (sistema capitalista).

Entretanto, evoluiu-se para uma concepção de trabalho como intrinsecamente relacionado à dignidade da pessoa humana trabalhadora, principalmente após as revoltas operárias de 1848 na Europa, o fortalecimento do movimento operário, em fins do século XIX, por meio das trade unions, a consolidação da Doutrina Social da Igreja a partir da Rerum Novarum, de Leão XIII, em 1891 e a criação, em 1919, da Organização Internacional do Trabalho.

A preocupação com os trabalhadores e a garantia de um trabalho digno também foi externalizada na Encíclica Laborem Exercens (sobre o trabalho humano), de 14 de setembro de 1981, do Papa João Paulo II:

(...) O trabalho é uma das características que distinguem o homem do resto das criaturas, cuja atividade relacionada com a manutenção da própria vida não se pode chamar trabalho; somente o homem tem capacidade para o trabalho (LE prefácio). (...) É preciso acentuar e pôr em relevo o primado do homem no processo de produção, o primado do homem em relação às coisas. E tudo aquilo que está contido no conceito de "capital", num sentido restrito do termo, é somente um conjunto de coisas. Ao passo que o homem, como sujeito do trabalho, independentemente do trabalho que faz, o homem, e só ele, é uma pessoa (LE 12f) (...) mesmo na época do "trabalho" cada dia mais mecanizado, o sujeito próprio do trabalho continua a ser o homem (LE 5c). (...) o trabalho era entendido e tratado como uma espécie de "mercadoria”, que o trabalhador — principalmente o operário da indústria - vendia ao dador de trabalho, que era, ao mesmo tempo, possessor do capital, isto é, do conjunto dos instrumentos de trabalho e dos meios que tornam possível a produção. Este modo de conceber o trabalho encontrava-se especialmente difundido na primeira metade do século XIX. Em seguida, as formulações explícitas deste gênero quase desapareceram, cedendo lugar a um modo mais humano de pensar e de avaliar o trabalho. (...) Apesar disso, o perigo de tratar o trabalho como uma "mercadoria sui generis" ou como uma "força” anônima necessária para a produção (fala-se mesmo de "força-trabalho") continua a existir ainda nos dias de hoje, especialmente quando a maneira de encarar a problemática econômica é caracterizada pela adesão às premissas do “economismo” materialista (LE 7b) (LESSA, 2004, p. 271-272, grifo do autor).

\footnotetext{
do ser humano na sua integridade física e psíquica, como autodeterminação consciente, garantida moral e juridicamente". Portanto, a dignidade da pessoa humana, incluído o trabalhador, é inerente à própria condição humana e não deve ser mitigada, pois, nesse caso, o homem - embora ser único e insubstituível — passará a ser tratado como mercadoria sujeita às trocas no mercado capitalista.
} 
Nesse contexto, deve-se garantir ao ser humano não apenas “trabalho”, mas o trabalho digno, enquanto direito humano, que respeita a pessoa humana em sua integralidade físico-psíquica, como ser único e insubstituível, sendo necessário para a garantia da subsistência digna do trabalhador e de sua família.

O trabalho digno está, pois, relacionado diretamente à dignidade da pessoa humana, sendo compreendido sob dois aspectos os quais integram a própria condição humana do trabalhador ${ }^{(5)}$ :

a) o intrínseco (subjetivo): como atributo pessoal e psíquico inerente ao ser humano, incluindo, por exemplo, a satisfação pessoal do trabalhador em realizar determinada atividade; a sensação de ser útil para a comunidade em que vive; ser merecedor de respeito e consideração por parte do Estado e dos particulares; ser livre para escolher satisfatoriamente seu trabalho etc.;

b) o extrínseco (objetivo): representando as condições materiais previstas na lei lato sensu em que o trabalho seria realizado, tais como: remuneração adequada e justa, sem discriminação de qualquer natureza; limite máximo e mínimo de duração da jornada de trabalho (diária e semanal); normas de higiene e segurança relacionadas ao meio ambiente do trabalho; concessão de férias, repouso semanal e feriados remunerados; licenças médicas em geral etc.

Logo, o trabalho digno é aquele adequadamente remunerado, exercido em condições de liberdade, igualdade, segurança, satisfação pessoal e capaz de garantir uma vida digna ao trabalhador e à sua família. Somente o trabalho digno está intimamente relacionado à dignidade da pessoa humana que, após a segunda metade do século XX, passou a ser incorporada nas ordens constitucionais de diversos países como a referência ética a inspirar o direito construído e positivado nos Estados Democráticos de Direito, inclusive no Brasil com a Constituição Federal de 1988.

Seguindo essa tendência, consagrou-se a necessidade de proteção do trabalho digno e, consequentemente, da dignidade do trabalhador, sendo diretrizes basilares da Organização Internacional do Trabalho e dos processos de integração regional, principalmente no caso do Mercosul.

\section{O Trabalho digno no ÂMbito da Organização Internacional do Trabalho}

Em 1919, a comissão especial da Conferência da Paz aprovou a Parte XIII do Tratado de Versailles, criando a Organização Internacional do Trabalho (OIT) — inicialmente vinculada à Sociedade das Nações Unidas e, a partir de 1945, incorporada à Organização das Nações Unidas (ONU) - , no intuito de conceder um tratamento uniformizado aos direitos dos trabalhadores, em nível internacional, fundamentado na justiça social. Em 1920, sua sede foi transferida para Genebra onde se encontra até o presente momento.

(5) Para maiores detalhes acerca do trabalho digno, consulte Gamba (2009). 
A OIT é uma organização internacional permanente com mandato constitucional, possuindo personalidade jurídica de Direito Público Internacional, sendo o órgão competente para estabelecer e disciplinar normas internacionais do trabalho e gozando de reconhecimento universal na promoção dos princípios da valorização do trabalho humano e da dignidade do trabalhador.

A Declaração de Filadélfía ${ }^{(6)}$ foi um dos mais expressivos documentos para a tutela dos direitos humanos dos trabalhadores, antecedendo a Declaração Universal dos Direitos Humanos que seria aprovada pelas Nações Unidas somente em 1948, ao estabelecer diretrizes norteadoras do trabalho digno (art. I):

a) o trabalho não é uma mercadoria;

b) a liberdade de expressão e de associação é uma condição indispensável a um progresso ininterrupto;

c) a penúria constitui um perigo para a prosperidade geral;

d) a luta contra a carência, em qualquer Estado, deve ser conduzida com infatigável energia e por um esforço internacional contínuo e conjugado, no qual os representantes dos empregadores e dos empregados discutam, em igualdade, com os dos governos e tomem com eles decisões de caráter democrático, visando ao bem comum.

Entretanto, a OIT caminhou ao longo do século XX concomitantemente com as mudanças sociais, econômicas e políticas, havendo a elaboração de outras declarações que vieram a acrescer novos contornos ao sistema internacional de garantia dos direitos humanos trabalhistas.

Em 19 de junho de 1998, foi assinada a Declaração relativa aos Princípios e Direitos Fundamentais no Trabalho na $86^{\underline{a}}$ Reunião da Conferência Internacional do Trabalho, em Genebra, reafirmando a obrigação universal de respeitar, promover e tornar realidade os princípios refletidos nas Convenções da $\operatorname{OIT}^{(7)}$.

Em seu art. $1^{\circ}$, essa Declaração estabelece que todos os Estados-membros, ao se incorporarem livremente à OIT, aceitaram os princípios e direitos enunciados na sua Constituição e na Declaração de Filadélfia, comprometendo-se a alcançar os objetivos gerais da Organização na medida de suas possibilidades os quais se cristalizaram nas convenções sob a forma de direitos e obrigações específicos reconhecidos dentro e fora da Organização (SÜSSEKIND, 2007).

$\mathrm{O}$ art. $2^{\underline{0}}$ declara que todos os Estados-membros, ainda que não tenham ratificado as convenções, têm compromisso com os seus princípios e finalidades porque pertencem à OIT, devendo respeitar e concretizar em suas realidades fáticas os direitos fundamentais

(6) Na $26^{\underline{a}}$ Reunião da Conferência Internacional do Trabalho, em 10 de maio de 1944, a OIT aprovou a Declaração de Filadélfia, servindo de modelo para a Carta da ONU de 1945.

(7) Em função dos limites do presente artigo, não serão analisadas especificamente as convenções da OIT. Para maiores detalhes, consulte Süssekind (2007). 
dos trabalhadores, a saber: a) liberdade sindical e reconhecimento efetivo do direito de negociação coletiva; b) eliminação de todas as formas de trabalho forçado ou obrigatório; c) abolição efetiva do trabalho infantil; e d) eliminação da discriminação em matéria de emprego e ocupação (SÜSSEKIND, 2007).

Finalmente, em junho de 2008, na 97ํㅗㅡ Reunião Anual da Conferência Internacional do Trabalho, foi aprovada a Declaração sobre a Justiça Social para uma Globalização Equitativa no intuito de reforçar a promoção do direito ao trabalho digno e enfrentar os crescentes desafios da globalização. No século XXI, essa Declaração possui um papel histórico de extraordinária importância porque busca centralizar esforços dos Estados, dos povos e da comunidade internacional na implementação do trabalho digno, sendo aprovada no âmbito de um processo mundial em que se verifica a ocorrência do aumento dos preços dos alimentos e da energia, de movimentos especulativos e crise financeira, do agravamento do desemprego, das situações de pobreza e da exclusão social.

$\mathrm{Na}$ seção I, a Declaração apresenta quatro princípios básicos, viabilizadores do trabalho digno, como elemento central das políticas sociais e econômicas a serem adotadas, in verbis:

i) promover el empleo creando un entorno institucional y económico sostenible en cuyo marco:

- las personas puedan adquirir y actualizar las capacidades y competencias que necesitan para poder trabajar de manera productiva en aras de su propia realización personal y el bienestar común;

- todas las empresas, tanto públicas como privadas, sean sostenibles para hacer posible el crecimiento y la generación de mayores oportunidades y perspectivas de empleo e ingresos para todos;

— la sociedad pueda conseguir sus objetivos de desarrollo económico y de progreso social, así como alcanzar un buen nivel de vida;

ii) adoptar y ampliar medidas de protección social - seguridad social y protección de los trabajadores - que sean sostenibles y estén adaptadas a las circunstancias nacionales, con inclusión de:

— la ampliación de la seguridad social a todas las personas, incluidas medidas para proporcionar ingresos básicos a quienes necesiten esa protección, y la adaptación de su alcance y cobertura para responder a las nuevas necesidades e incertidumbres generadas por la rapidez de los cambios tecnológicos, sociales, demográficos y económicos;

— condiciones de trabajo saludables y seguras, y

- medidas en materia de salarios y ganancias y de horas y otras condiciones de trabajo, destinadas a garantizar a todos una justa distribución de los frutos del progreso y un salario mínimo vital para todos los que tengan empleo y necesiten esa clase de protección; 
iii) promover el dialogo social y el tripartismo como los métodos más apropiados para:

— adaptar la aplicación de los objetivos estratégicos a las necesidades y circunstancias de cada país;

- traducir el desarrollo económico en progreso social y el progreso social en desarrollo económico;

- facilitar la creación de consenso respecto de las políticas nacionales e internacionales que inciden en las estrategias y programas en materia de empleo y trabajo decente;

- fomentar la eficacia de la legislación y las instituciones laborales, en particular respecto del reconocimiento de la relación de trabajo, la promoción de buenas relaciones laborales y el establecimiento de sistemas eficaces de inspección del trabajo;

iv) respetar, promover y aplicar los principios y derechos fundamentales en el trabajo, que revisten particular importancia, no sólo como derechos sino también como condiciones propicias, necesarias para la plena realización de todos los objetivos estratégicos, teniendo en cuenta:

- que la libertad de asociación y la libertad sindical y el reconocimiento efectivo del derecho de negociación colectiva son particularmente importantes para permitir el logro de esos cuatro objetivos estratégicos;

— que la violación de los principios y derechos fundamentales en el trabajo no puede invocarse ni utilizarse de modo alguno como ventaja comparativa legítima y que las normas del trabajo no deberían utilizarse con fines comerciales proteccionistas (OIT, 2009).

Portanto, a Declaração de Filadélfia (1944), a Declaração relativa aos Princípios e Direitos Fundamentais do Trabalho (1998) e a Declaração sobre a Justiça Social para uma Globalização Equitativa (2008) significam um importante passo no respeito, na promoção e na garantia do trabalho digno em nível internacional, devendo ser incorporado nas ordens jurídicas dos Estados, em especial no âmbito dos processos de integração regional, no intuito de consolidar a primazia da dignidade da pessoa humana trabalhadora e de assegurar aos trabalhadores uma participação equânime e justa na distribuição da riqueza gerada no capitalismo, no intuito de desenvolver a igualdade de oportunidades a todas as pessoas.

\section{A Concretização do trabalho digno na integração regional: o Mercosul}

Após a Segunda Guerra Mundial, concomitantemente com a internacionalização

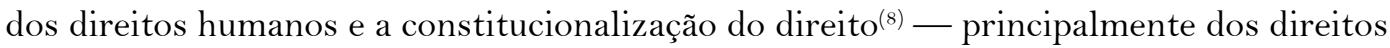

(8) De acordo com Barroso (2009), “a ideia de constitucionalização do Direito (...) está associada a um efeito expansivo das normas constitucionais, cujo conteúdo material e axiológico se irradia, com força normativa, por todo o sistema jurídico. Os valores, os fins públicos e os comportamentos contemplados nos princípios e regras da 
sociais de cunho laboral - , consolidou-se na ordem internacional a integração regional, destacando-se, no âmbito da América Latina, o Mercado Comum do Sul (Mercosul). Anteriormente à sua constituição, já houve outras tentativas de formação de blocos econômicos latino-americanos que não prosperaram, tais como: a Associação Latino-americana de Livre Comércio (ALALC) ${ }^{(9)}$ e a Associação Latino-americana de Integração $(\mathrm{ALADI})^{(10)}$.

Normalmente, os blocos econômicos de integração regional(11), como é o caso do Mercosul, objetivam o fortalecimento econômico e político regional dos Estados-membros com vistas à maior competitividade no âmbito do comércio mundial. Logo, o termo “integração" implica em noções como interdependência, corresponsabilidade, complementaridade e, principalmente, solidariedade(12) entre os Estados no mundo contemporâneo, marcado pela redução da autonomia dos Estados na elaboração das políticas interna e externa e pela imperiosidade na formulação de regimes internacionais que possibilitem a resolução de problemas comuns.

Nesse contexto, o Mercosul se originou de diversas negociações entre o Brasil e a Argentina ocorridas durante a década de 1980, sendo impulsionadas pelo processo de redemocratização dos países latino-americanos que encerrou um longo período de governos autoritários. As relações conflituosas entre a Argentina e o Brasil se transformaram em relações internacionais pautadas na cooperação e permitiram, em 1985, a assinatura da Declaração de Iguaçu.

Posteriormente, em 1988, foi assinado o Tratado Bilateral de Integração, Cooperação e Desenvolvimento, prevendo a formação de um espaço econômico comum entre ambos os países e, em 1990, foi assinada a "Ata de Bueno Aires”, dispondo acerca da constituição de um Mercado Comum. Finalmente, em 26 de março de 1991, o Paraguai e o Uruguai se associaram ao Brasil e à Argentina e manifestaram seu interesse em participar desse grupo, assinando o Tratado de Assunção que se constituiu no marco jurídico-institu-

Constituição passam a condicionar a validade e o sentido de todas as normas do direito infraconstitucional. Como intuitivo, a constitucionalização repercute sobre a atuação dos três Poderes, inclusive e notadamente nas suas relações com os particulares. Porém, mais original ainda: repercute, também, nas relações entre particulares”.

(9) A ALALC foi criada, em 18.2.1960, mediante a assinatura do Tratado de Montevidéu entre Argentina, Brasil, Chile, México, Paraguai, Peru e Uruguai, obtendo, nos anos seguintes, a adesão de outros países latino-americanos e tendo como meta a implantação de um mercado comum entre seus membros.

(10) Em 12.8.1980, foi constituída a ALADI pelo Tratado de Montevidéu, possuindo como países integrantes Brasil, Argentina, Bolívia, Chile, Colômbia, Equador, México, Paraguai, Peru, Uruguai e Venezuela, sendo, de certo modo, uma sucessora na ALALC, pois objetivava a instituição, a longo prazo, de um mercado comum latino-americano.

(11) "Os blocos econômicos de integração regional podem ser definidos como o processo segundo o qual Estados de um dado espaço geográfico comum se unem para integrar setores de sua economia, arregimentar parceiros comerciais e implementar práticas mercantis que possuam repercussões transnacionais, com a abertura comum de suas fronteiras e integração de sua economia” (MENEZES, 2009, p. 159).

(12) "A solidariedade designa um vínculo recíproco e profundo que liga dois ou mais sujeitos, ou mesmo um grupo, no sentido da consciência de responsabilidade comum sobre um determinado objeto, ou de um elemento comum que os une, e em razão desses laços, há uma tendência natural de ajudar o outro e de compartilhar os mesmos valores, sem exigir nada em troca, sejam eles bons ou não, encerrem eles benefícios ou custos, manifestados mediante a concordância dos interesses dos sujeitos envolvidos. Além disso, ela também expressa uma corresponsabilidade no sentido de cumprir uma obrigação, um dever assumido em grupo por ocasião de um pacto” (MENEZES, 2009, p. 243). 
cional $^{(13)}$ na criação do Mercado Comum do Sul. A Venezuela, em 4 de julho de 2006, assinou o Protocolo de Adesão ao Mercosul $^{(14)}$ e, até o presente momento, Bolívia, Chile, Peru, Colômbia e Equador estão na qualidade de países associados.

$\mathrm{O}$ art. $1^{\circ}$ do Tratado de Assunção previu, dentre outros propósitos, que o Mercosul seria um mercado comum baseado na livre circulação de bens, serviços e fatores produtivos mediante a eliminação dos direitos alfandegários e das restrições não tarifárias à circulação de mercadorias e de qualquer outra medida de efeito equivalente e baseado, também, na coordenação de políticas macroeconômicas e setoriais — de comércio exterior, agrícola, industrial, fiscal, monetária, cambial e de capitais, de outras que se acordem - a fim de assegurar condições adequadas de concorrência entre os Estados-partes.

Logo, o Mercosul assumiu mais uma feição de aliança comercial com vistas a dinamizar a economia regional, tendo o desafio de sua conversão em mercado comum com a implantação da livre circulação de bens, serviços, pessoas ${ }^{(15)}$ e capitais. Os tratados que fundamentaram a criação e a institucionalização do Mercosul não se preocuparam com as políticas sociais e de trabalho a serem desenvolvidas para a viabilização da integração latino-americana, não havendo, ainda, qualquer menção aos direitos humanos dos trabalhadores e ao direito ao trabalho digno os quais devem pautar as relações firmadas entre capital e trabalho no âmbito desse bloco regional.

Para minimizar essa situação, em 10 de dezembro de 1998, foi firmada a Declaração Sociolaboral do Mercosul, pelos presidentes da Argentina, Brasil, Paraguai e Uruguai, no intuito de expressar uma opção dos Estados-membros para o desenvolvimento de um modelo de integração que fosse capaz de harmonizar desenvolvimento econômico e bem-estar social, enfocando o emprego produtivo e o trabalho digno nas políticas e nos programas a serem desenvolvidos no bloco.

Essa declaração prevê a tutela dos seguintes direitos humanos trabalhistas, no intuito de se resguardar o trabalho digno nas relações mercosulistas (Mercosul, 2009):

(13) Posteriormente, os Estados-membros firmaram diversos pactos internacionais, destacando-se: o Protocolo de Ouro Preto (1994) que dispôs sobre a estrutura institucional do Mercosul, conferindo-lhe personalidade jurídica de direito público internacional; o Protocolo de Olivos para a Solução de Controvérsias no bloco (2002) que, ao substituir o Protocolo de Brasília (1991), criou um Tribunal Permanente de Revisão para julgar, em nível recursal, as decisões proferidas pelos tribunais arbitrais ad hoc e o Protocolo Constitutivo do Parlamento do Mercosul (2005) que previu, dentre outros propósitos, a consolidação da integração latino-americana e a promoção da solidariedade e da cooperação regional e internacional.

(14) O Protocolo de Adesão dispõe expressamente que: "Art. 10. A partir da data da entrada em vigência do presente Protocolo, a República Bolivariana da Venezuela adquirirá a condição de Estado Parte e participará com todos os direitos e obrigações no Mercosul, de acordo com o art. $2^{\circ}$ do Tratado de Assunção e nos termos do presente Protocolo. (...) Art. 12. O presente Protocolo, instrumento adicional ao Tratado de Assunção, entrará em vigência no trigésimo dia contado a partir da data de depósito do quinto instrumento de ratificação. A República do Paraguai será depositária do presente Protocolo e dos instrumentos de ratificação e notificará às Partes a data dos depósitos desses instrumentos. Feito na cidade de Caracas, República Bolivariana da Venezuela, aos quatro dias do mês de julho de dois mil e seis em um original, nos idiomas português e espanhol, sendo ambos os textos igualmente autênticos" (MERCOSUL, 2010)

(15) Na circulação de pessoas no âmbito do Mercosul, estão incluídos os trabalhadores que, muitas vezes, são tratados pelo sistema capitalista apenas como mão de obra integrante dos custos da produção. Entretanto, o trabalho não é mercadoria e nem insumo de produção, mas se apresenta como um valor necessário para a existência digna da pessoa humana trabalhadora. 
a) não discriminação: todo trabalhador tem garantida a igualdade efetiva de direitos, tratamento e oportunidades no emprego e ocupação, sem distinção ou exclusão por motivo de raça, origem nacional, cor, sexo ou orientação sexual, idade, credo, opinião política ou sindical, ideologia, posição econômica ou qualquer outra condição social ou familiar, em conformidade com as disposições legais vigentes. Os Estados-partes comprometem-se a garantir a vigência deste princípio de não discriminação. Em particular, comprometem-se a realizar ações destinadas a eliminar a discriminação no que tange aos grupos em situação desvantajosa no mercado de trabalho (art. $1^{\circ}$ );

b) promoção da igualdade: as pessoas portadoras de necessidades especiais serão tratadas de forma digna e não discriminatória, favorecendo-se sua inserção social e no mercado de trabalho. Os Estados-partes comprometem-se a adotar medidas efetivas, especialmente no que se refere à educação, formação, readaptação e orientação profissional, à adequação dos ambientes de trabalho e ao acesso aos bens e serviços coletivos, a fim de assegurar que as pessoas portadoras de necessidades especiais tenham a possibilidade de desempenhar uma atividade produtiva (art. $\left.2^{\underline{o}}\right)$. Os Estados-partes comprometem-se a garantir, mediante a legislação e práticas trabalhistas, a igualdade de tratamento e oportunidades entre mulheres e homens $\left(\right.$ art. $3^{\stackrel{o}{ })}$;

c) proteção aos trabalhadores migrantes e fronteiriços: todos os trabalhadores migrantes, independentemente de sua nacionalidade, têm direito à ajuda, informação, proteção e igualdade de direitos e condições de trabalho reconhecidos aos nacionais do país em que estiverem exercendo suas atividades. Os Estados-partes comprometem-se a adotar medidas tendentes ao estabelecimento de normas e procedimentos comuns relativos à circulação dos trabalhadores nas zonas de fronteira e a levar a cabo as ações necessárias para melhorar as oportunidades de emprego e as condições de trabalho e de vida destes trabalhadores (art. $4^{\circ}$ );

d) eliminação do trabalho forçado: toda pessoa tem direito ao trabalho livre e a exercer qualquer ofício ou profissão, de acordo com as disposições nacionais vigentes. Os Estados-partes comprometem-se a eliminar toda forma de trabalho ou serviço exigido a um indivíduo sob a ameaça de uma pena qualquer e para o qual dito indivíduo não se ofereça voluntariamente. Ademais, comprometem-se a adotar medidas para garantir a abolição de toda utilização de mão de obra que propicie, autorize ou tolere o trabalho forçado ou obrigatório. De modo especial, suprime-se toda forma de trabalho forçado ou obrigatório que possa utilizar-se: a) como meio de coerção ou de educação política ou como castigo por não ter ou expressar determinadas opiniões políticas, ou por manifestar oposição ideológica à ordem política, social ou econômica estabelecida; b) como método de mobilização e utilização da mão de obra com fins de fomento econômico; c) como medida de disciplina no trabalho; d) como castigo por haver participado em greves; e) como medida de discriminação racial, social, nacional ou religiosa (art. $5^{\circ}$ ); 
e) tutela do trabalho infantil e de menores: a idade mínima de admissão ao trabalho será aquela estabelecida conforme as legislações nacionais dos Estados-partes, não podendo ser inferior àquela em que cessa a escolaridade obrigatória. Os Estados-partes comprometem-se a adotar políticas e ações que conduzam à abolição do trabalho infantil e à elevação progressiva da idade mínima para ingressar no mercado de trabalho. O trabalho dos menores será objeto de proteção especial pelos Estados Partes, especialmente no que concerne à idade mínima para o ingresso no mercado de trabalho e a outras medidas que possibilitem seu pleno desenvolvimento físico, intelectual, profissional e moral. A jornada de trabalho para esses menores, limitada conforme as legislações nacionais, não admitirá sua extensão mediante a realização de horas extras nem em horários noturnos. $\mathrm{O}$ trabalho dos menores não deverá realizar-se em um ambiente insalubre, perigoso ou imoral, que possa afetar o pleno desenvolvimento de suas faculdades físicas, mentais e morais. A idade de admissão a um trabalho com alguma das características antes assinaladas não poderá ser inferior a 18 anos (art. $6^{\underline{o}}$ );

f) liberdade de associação: todos os empregadores e trabalhadores têm o direito de constituir as organizações que considerem convenientes, assim como de afiliar-se a essas organizações, em conformidade com as legislações nacionais vigentes. Os Estados-partes comprometem-se a assegurar, mediante dispositivos legais, o direito à livre associação, abstendo-se de qualquer ingerência na criação e gestão das organizações constituídas, além de reconhecer sua legitimidade na representação e na defesa dos interesses de seus membros (art. $8^{\underline{o}}$ );

g) liberdade sindical: os trabalhadores deverão gozar de adequada proteção contra todo ato de discriminação tendente a menoscabar a liberdade sindical com relação a seu emprego. Deverá garantir-se: a) a liberdade de filiação, de não filiação e desfiliação, sem que isto comprometa o ingresso em um emprego ou sua continuidade no mesmo; b) evitar demissões ou prejuízos a um trabalhador por causa de sua filiação sindical ou de sua participação em atividades sindicais; c) o direito de ser representado sindicalmente, de acordo com a legislação, acordos e convênios coletivos de trabalho em vigor nos Estados-partes (art. $9^{\circ}$ );

h) negociação coletiva: os empregadores ou suas organizações e as organizações ou representações de trabalhadores têm direito de negociar e celebrar convenções e acordos coletivos para regular as condições de trabalho, em conformidade com as legislações e práticas nacionais (art. 10) $)^{(16)}$;

i) garantia do direito de greve: todos os trabalhadores e as organizações sindicais têm garantido o exercício do direito de greve, conforme as disposições nacionais

(16) A representação sindical do Brasil reservou-se o direito de não adesão à redação proposta para o art. 10, especificamente quanto à admissão da negociação e contratação coletiva sem representação sindical, pois fere o arcabouço jurídico que disciplina a atuação dos sindicatos na representação dos trabalhadores. 
vigentes. Os mecanismos de prevenção ou solução de conflitos ou a regulação deste direito não poderão impedir seu exercício ou desvirtuar sua finalidade (art. 11);

j) promoção e desenvolvimento de procedimentos preventivos e de autocomposição de conflitos: os Estados-partes comprometem-se a propiciar e desenvolver formas preventivas e alternativas de autocomposição dos conflitos individuais e coletivos de trabalho, fomentando a utilização de procedimentos independentes e imparciais de solução de controvérsias (art. 12);

1) promoção do diálogo social: os Estados-partes comprometem-se a fomentar o diálogo social nos âmbitos nacional e regional, instituindo mecanismos efetivos de consulta permanente entre representantes dos governos, dos empregadores e dos trabalhadores, a fim de garantir, mediante o consenso social, condições favoráveis ao crescimento econômico sustentável e com justiça social da região e a melhoria das condições de vida de seus povos (art. 13);

m) fomento ao emprego: os Estados-partes comprometem-se a promover o crescimento econômico, a ampliação dos mercados interno e regional e a executar políticas ativas referentes ao fomento e criação do emprego, de modo a elevar o nível de vida e corrigir os desequilíbrios sociais e regionais (art. 14);

n) proteção dos desempregados: os Estados-partes comprometem-se a instituir, manter e melhorar mecanismos de proteção contra o desemprego, compatíveis com as legislações e as condições internas de cada país, a fim de garantir a subsistência dos trabalhadores afetados pela desocupação involuntária e ao mesmo tempo facilitar o acesso a serviços de recolocação e a programas de requalificação profissional que facilitem seu retorno a uma atividade produtiva (art. 15);

o) formação profissional e desenvolvimento de recursos humanos: todos os trabalhadores têm direito à orientação, à formação e à capacitação profissional. Os Estados-partes comprometem-se a instituir, com as entidades envolvidas que voluntariamente assim o desejem, serviços e programas de formação ou orientação profissional contínua e permanente, de maneira a permitir aos trabalhadores obter as qualificações exigidas para o desempenho de uma atividade produtiva, aperfeiçoar e reciclar os conhecimentos e habilidades, considerando fundamentalmente as modificações resultantes do progresso técnico. Os Estados-partes obrigam-se ademais a adotar medidas destinadas a promover a articulação entre os programas e serviços de orientação e formação profissional, por um lado, e os serviços públicos de emprego e de proteção dos desempregados, por outro, com o objetivo de melhorar as condições de inserção laboral dos trabalhadores. Os Estados-partes comprometem-se a garantir a efetiva informação sobre os mercados de trabalho e sua difusão tanto em nível nacional como regional (art. 16);

p) proteção da saúde e segurança no trabalho: todo trabalhador tem o direito de exercer suas atividades em um ambiente de trabalho sadio e seguro, que preserve 
sua saúde física e mental e estimule seu desenvolvimento e desempenho profissional. Os Estados-partes comprometem-se a formular, aplicar e atualizar em forma permanente e em cooperação com as organizações de empregadores e de trabalhadores, políticas e programas em matéria de saúde e segurança dos trabalhadores e do meio ambiente de trabalho, a fim de prevenir os acidentes de trabalho e as enfermidades profissionais, promovendo condições ambientais propícias para o desenvolvimento das atividades dos trabalhadores (art. 17);

p) inspeção do trabalho: todo trabalhador tem direito a uma proteção adequada no que se refere às condições e ao ambiente de trabalho. Os Estados-partes comprometem-se a instituir e a manter serviços de inspeção do trabalho, com o propósito de controlar em todo o seu território o cumprimento das disposições normativas que dizem respeito à proteção dos trabalhadores e às condições de segurança e saúde no trabalho (art. 18);

q) seguridade social: os trabalhadores do Mercosul têm direito à seguridade social, nos níveis e condições previstos nas respectivas legislações nacionais. Os Estados-partes comprometem-se a garantir uma rede mínima de amparo social que proteja seus habitantes frente à contingência de riscos sociais, enfermidades, velhice, invalidez e morte, buscando coordenar as políticas na área social, de forma a suprimir eventuais discriminações derivadas da origem nacional dos beneficiários (art. 19).

Dessa maneira, a Declaração Sociolaboral não seria uma "obra acabada, mas instituto em permanente construção, em sintonia com o processo integrador e os pactos de governos e atores coletivos em prol da dimensão humana do Mercosul. Os Estados-partes dedicam-se, hoje, a revisar o documento, no intuito de adequá-lo às mudanças operadas nas estruturas jurídicas e socioeconômicas do bloco e, sobretudo, de conferir-lhe maior vigência e eficácia. Aqui reside o desafio central que envolve a Declaração, qual seja, o de transformá-la em plataforma impulsora de mais e melhores oportunidades de trabalho para [os] povos" (MERCOSUL, 2009).

\section{Conclusão}

O trabalho digno é um valor necessário para a existência digna do trabalhador, estando relacionado à dignidade humana e sendo compreendido sob dois aspectos: o intrínseco (subjetivo) como atributo pessoal e psíquico inerente ao ser humano e o extrínseco (objetivo) como as condições materiais em que o trabalho é realizado. Logo, o trabalho digno é aquele adequadamente remunerado, exercido em condições de liberdade, igualdade, segurança, satisfação pessoal e capaz de garantir uma vida digna ao trabalhador e à sua família.

O trabalho deve ser protegido como obrigação social imposta aos Estados, à comunidade e aos particulares e não na condição de mercadoria ou insumo de produção como o capitalismo procurou difundir. Assim, deve-se garantir ao ser humano não apenas o 
"trabalho", mas o trabalho digno - que respeita a pessoa humana trabalhadora em sua integralidade físico-psíquica como ser único e insubstituível —, sobretudo no âmbito dos processos de integração regional como é o caso do Mercosul.

Essa concepção de trabalho digno, intrinsecamente relacionado à dignidade do trabalhador, fortaleceu-se no século XX com a criação, em 1919, da Organização Internacional do Trabalho que, mediante convenções internacionais e declarações, estabeleceu diretrizes, políticas e princípios para o respeito, a promoção e a garantia do trabalho digno em nível internacional.

Os Estados-membros do Mercosul são também membros da Organização Internacional do Trabalho e ratificaram as principais convenções que garantem os direitos fundamentais dos trabalhadores, inclusive a Declaração de Filadélfia (1944), a Declaração relativa aos Princípios e Direitos Fundamentais do Trabalho (1998) e a Declaração sobre a Justiça Social para uma Globalização Equitativa (2008), devendo adotar políticas públicas e ações para a promoção do emprego, de condições mais equânimes e justas de trabalho, diálogo social, enfim, a concretização do trabalho digno.

Ademais, no âmbito do Mercosul, os Estados-membros adotaram a Declaração Sociolaboral (1998), no intuito de implementar no bloco um modelo de integração embasado na interdependência, corresponsabilidade, complementaridade e na solidariedade, sendo capaz de harmonizar o desenvolvimento econômico e o bem-estar social e concretizando o trabalho digno nas políticas públicas e nas ações a serem desenvolvidas.

Essa declaração - apesar de não ser um tratado internacional e não possuir, $a$ princípio, força normativa vinculante - representa uma carta de intenções ou declaração de direitos e não pode ser desprezada como norma integrante do direito de integração mercossulista, sobretudo em face do seu conteúdo protetivo dos direitos humanos dos trabalhadores, notadamente do chamado trabalho digno.

Neste sentido, Comparato (2007, p. 227) preceitua que "reconhece-se hoje, em toda a parte, que a vigência dos direitos humanos independe de sua declaração em constituições, leis e tratados internacionais, exatamente porque se está diante de exigências de respeito à dignidade humana, exercidas contra todos os poderes estabelecidos, oficiais ou não”.

Resta evidente que a concretização do trabalho digno no Mercosul, mediante programas e ações, requer significativo comprometimento e atuação política dos governos dos Estados-membros, pois já está amplamente previsto nas normas internacionais, principalmente da OIT, e na Declaração Sociolaboral mercossulista.

No âmbito dos processos de integração regional, em especial no caso do Mercosul, a concretização do trabalho digno somente ocorrerá mediante um efetivo “querer político" que consolidará a primazia da dignidade da pessoa humana trabalhadora e assegurará aos trabalhadores uma participação equânime e justa na distribuição da riqueza gerada no capitalismo, no intuito de se desenvolver a igualdade de oportunidades a todas as pessoas, independentemente de classe social, raça, sexo, idade, qualificação profissional, etc. 
A ampla tutela normativa do trabalho digno, por si só, não representa a garantia de sua efetivação no mundo do trabalho, devendo os Estados agir positivamente para sua implementação, pois consoante Bobbio (2004, p. 43, grifo do autor) já anteviu: “o problema fundamental em relação aos direitos do homem, hoje, não é tanto o de justificá-los, mas o de protegêe-los. Trata-se de um problema não filosófico, mas político”.

É impossível que o Mercosul “caminhe” para uma integração regional mais equânime e solidária para os povos da América Latina e para a constituição de uma comunidade latino-americana de nações sem que haja a concretização do trabalho digno - e consequentemente dos direitos humanos dos trabalhadores — mediante ações e políticas públicas efetivas que busquem maior desenvolvimento econômico e minimização do desemprego com justiça social, havendo, ainda, um longo caminho a ser percorrido pelos países integrantes do bloco mercosulista.

Assim, todo o ser humano, em especial o trabalhador, deve ser sempre visto como um fim em si mesmo, possuidor de um valor (a sua dignidade) e não como mera mercadoria descartável, sendo-lhe garantido políticas públicas de trabalho que promovam sua integração social na comunidade e sua recolocação profissional no mercado de trabalho, contribuindo para a implementação do pleno emprego e concretizando o trabalho digno. Somente com a valorização do homem - enquanto ser que sobrevive, trabalha e interage com outros - e com o respeito de suas diferenças pelo Direito, pelos Estados e pela comunidade haverá a construção de um mundo mais justo e solidário.

\section{REFERÊNCIAS}

ABBAGNANO, Nicola. Dicionário de filosofia. 5. ed. Revisão da tradução e tradução dos novos textos Ivone Castilho Benedetti. São Paulo: Martins Fontes, 2007.

AMARAL JUNIOR, Alberto do. Introdução ao direito internacional público. São Paulo: Atlas, 2008.

BARROSO, Luís Roberto. Neoconstitucionalismo e constitucionalização do direito. O triunfo tardio do direito constitucional no Brasil. Jus Navigandi, Teresina, ano 9, n. 851, 1ํ․1 1.2005. Disponível em: <http://jus2.uol.com.br/doutrina/texto.asp?id=7547> Acesso em: 7.11.2009.

BOBBIO, Norberto. A era dos direitos. Tradução de Carlos Nelson Coutinho, Apresentação de Celso Lafer. Rio de Janeiro: Campus Elsevier, 2004.

BOTTOMORE, Tom; OUTHWAITE, William. Dicionário do pensamento social do século XX. Tradução de Eduardo Francisco Alves e Álvaro Cabral. Rio de Janeiro: Jorge Zahar, 1996.

COMPARATO, Fábio Konder. A afirmação histórica dos direitos humanos. 3. ed. São Paulo: Saraiva, 2007.

DICIONÁRIO Houaiss de Língua Portuguesa. disponível em: <http://www.houaiss.uol.com.br > Acesso em: 8.7.2008.

GAMBA, Juliane Caravieri Martins. Frentes de trabalho e a dignidade da pessoa humana: redimensionamento das políticas públicas à luz dos direitos humanos e da Constituição de 1988. São Paulo, 2009. Dissertação (Mestrado em Direito do Estado) - Pontifícia Universidade Católica de São Paulo. 
GARCIA, Maria. Limites da ciência: a dignidade da pessoa humana, a ética da responsabilidade. São Paulo: Revista dos Tribunais, 2004.

JOHNSON, Allan G. Dicionário de sociologia: guia prático da linguagem sociológica. Tradução de Ruy Jungmann e consultoria de Renato Lessa. Rio de Janeiro: Jorge Zahar, 1997.

KANT, Immanuel. Fundamentação da metafísica dos costumes e outros escritos. Tradução de Leopoldo Holzbach. São Paulo: Martin Claret, 2008.

LESSA, Luiz Carlos. Dicionário da doutrina social da igreja: doutrina social da Igreja de A a Z. São Paulo: LTr, 2004.

MARX, Karl. Manuscritos econômico-filosóficos. 2. ed. Tradução, apresentação e notas de Jesus Ranieri. São Paulo: Boitempo, 2007.

. Trabalho assalariado e capital \&̊ salário, preço e lucro. São Paulo: Expressão Popular, 2006.

MENEZES, Wagner. Direito internacional na América Latina. Curitiba: Juruá, 2009.

MERCOSUL. Declaração sociolaboral do Mercosul: 10 anos da DSL. Edição Comemorativa. Disponível em: <http://www.mte.gov.br/eventos/mercosul/decl_pt.pdf> Acesso em: 7.11.2009.

. Protocolo de adesão da República Bolivariana da Venezuela. Disponível em: <http:// www.mercosul.gov.br> Acesso em: $1^{\circ}$.5.2010.

OIT. Agenda nacional de trabalho decente. XVI Reunião Regional Americana. Brasília, maio 2006. Disponível em: <http://www.ilo.org/publns> Acesso em: 18.11.2008.

Declaração sobre a justiça social para uma globalização equitativa. Texto em língua espanhola. OIT - Escritório de Portugal. Disponível em: <http://www.ilo.org/public/portugue/region/ eurpro/lisbon/html/portugal_cit_97_pt.htm>Acesso em: 9.3.2009.

ROCHA, José Manuel de Sacadura. Antropologia jurídica, para uma filosofia antropológica do direito. Rio de Janeiro: Elsevier, 2008.

ROMAR, Carla Teresa Martins. Direito do trabalho e dignidade da pessoa humana. In: MIRANDA, Jorge; SILVA, Marco Antonio Marques da (coords.). Tratado luso-brasileiro da dignidade humana. São Paulo: Quartier Latin, 2008.

SANTOS, Boaventura de Sousa. Introdução a uma ciência pós-moderna. Rio de Janeiro: Graal, 1989.

SHERMAN, Howard J.; HUNT, E. K. História do pensamento econômico. 19. ed. Tradução de Jaime Larry Benchimol. Petrópolis: Vozes, 2000.

SILVA, De Plácido e. Vocabulário jurídico. 26. ed. Atualizadores Nagib Slaibi Filho e Gláucia Carvalho. Rio de Janeiro: Forense, 2005.

SUPIOT, Alain. Homo juridicus: ensaio sobre a função antropológica do direito. Tradução de Maria Ermantina de Almeida Prado Galvão. São Paulo: Martins Fontes, 2007.

SÜSSEKIND, Arnaldo. Convenções da OIT e outros tratados. 3. ed. São Paulo: LTr, 2007. 